Pre-print version. Political Studies Review 13 (4): 566.

\title{
Fineman and Grear's Vulnerability: Reflections on a New Ethical Foundation for Law and Politics
}

Martha Albertson Fineman and Anna Grear (2013) Vulnerability: Reflections on a New Ethical Foundation for Law and Politics. Farnham: Ashgate. 223pp, $£ 35.00$ (p/b), ISBN 9781472421630

\section{Nicolás Brando}

The essays compiled in this book offer a varied look at the theoretical implications, and the possible practical applications of Martha Albertson Fineman's critique of the liberal paradigm in the United States and of her "Vulnerability theory". The first chapter, written by Fineman, presents her critique of the liberal institutional bias of thinking of individuals as autonomous and independent subjects, and opposes it to her own more egalitarian thesis that sees individuals as universally vulnerable subjects who are naturally dependent on others. This "universal vulnerability" implies that our social institutions should be responsive to our innate dependency, hence focusing on promoting our resilience to harm, rather than fostering the unreachable autonomy of the individual.

Despite that most of the chapters are written by legal scholars, the targeted audience goes well beyond the field of law, touching subjects of philosophy, political science, sociology, or public policy, among others. The first five essays present a theoretical analysis of Fineman's theory, looking at its philosophical credentials, and as a critical framework for analyzing our current social order. The last five chapters apply the theoretical framework to specific empirical cases, such as local businesses, social housing policy, the distribution of assisted reproductive technology, vulnerability in the European Court of Human Rights, and animal rights' theory.

The wide spectrum of subjects touched by this compilation proves the relevance of 'vulnerability' as a theoretical framework for analyzing the impact of liberalism on our conception of the self. It makes us question many of our deepest prejudices of the individual as an idealized and autonomous subject, showing how this can generate structural inequalities in our social institutions. At the same time, it presents 'vulnerability' as an alternative approach to justice and equality, offering empirical examples for how this framework better represents humans (and animals), and how, if implemented in legislation and public policy, it could have a major positive impact on individuals who are suffering from grave injustices in our current social order. 
Pre-print version. Political Studies Review 13 (4): 566.

However, it must be mentioned that the variety of subjects that the book tackles creates a lack of cohesion among the different chapters, demanding specialized knowledge of each discipline so to fully understand each of the essays. From this perspective, it seems that it is not meant to be read as an ensemble, but rather as a combination of various independent contributions from different disciplines to the vulnerability framework. 